\title{
CFD based parametric analysis of gas flow in a counter-flow wet scrubber system
}

\author{
Bashir Ahmed Danzomo ${ }^{1, *}$, Momoh-Jimoh Enyiomika Salami ${ }^{1}$, Raisuddin Mohd Khan ${ }^{1}$, \\ Mohd Iskhandar Bin Mohd Nor ${ }^{2}$
}

${ }^{1}$ Department of Mechatronics Engineering, International Islamic University, P. O. Box 10, 50728, Kuala Lumpur, Malaysia

${ }^{2}$ Chemical Engineering Department, University of Malaya, 50603, Kuala Lumpur, Malaysia

Email address:

bdzomo@gmail.com(B. A. Danzomo)

\section{To cite this article:}

Bashir Ahmed Danzomo, Momoh-Jimoh Enyiomika Salami, Raisuddin Mohd Khan, Mohd Iskhandar Bin Mohd Nor. CFD Based Parametric Analysis of Gas Flow in A Counter-Flow Wet Scrubber System. International Journal of Environmental Protection and Policy. Vol. 1, No. 2, 2013, pp. 16-23. doi: 10.11648/j.ijepp.20130102.11

\begin{abstract}
Environmental protection measures regarding industrial emissions and tightened regulations for air pollution led to the selection of a counter-flow wet scrubber system based on applicability and economic considerations. The flow dynamics of gas transporting particulate matter and gaseous contaminants is a key factor which should be considered in the scrubber design. In this study, gas flow field were simulated using ANSYS Fluent computational fluids dynamic (CFD) software based on the continuity, momentum and $k-\varepsilon$ turbulence model so as to obtain optimum design of the system, improve efficiency, shorten experimental, period and avoid dead zone. The result shows that the residuals have done a very good job of converging at minimum number of iterations and error of 1E-6. The velocity flow contours and vectors at the inlet, across the scrubbing chamber and the outlet shows a distributed flow and the velocity profiles have fully conformed to the recommended profile for turbulent flows in pipes. The total pressure within the scrubber cross-section is constant while the minimum and maximum pressure drops was obtained to be $0.30 \mathrm{pa}$ and $3.03 \mathrm{pa}$ which has conformed to the recommended pressure drop for wet scrubbers. From the results obtained, it can be deduced that the numerical simulation using CFD is an effective method to study the flow characteristics of a counter-flow wet scrubber system.
\end{abstract}

Keywords: Computational Fluid Dynamics, Counter-Flow Wet Scrubber, Parametric Analysis, Gas Flow

\section{Introduction}

A counter-flow wet scrubber system is an air pollution control device that uses liquid spray to control particles contained in a particulate matter (PM) and gaseous contaminants that are being emitted from industrial production. The simplest type of the scrubber is the cylindrical or rectangular system in which air and contaminants passes into a chamber where it contacts a liquid spray produced by spray nozzles located across the flow passage. As indicated by [1], counter-flow scrubbers have important advantage when compared to other air pollution control devices. They can collect flammable and explosive dusts safely, absorb gaseous pollutants, collect mists, cool hot gas streams and it has the potential to save 35 to 40 percent over the cost of conventional air pollution control equipment for brick kilns while meeting new standards for the control of waste gas (dust) emissions from cement fabrication, hydrogen fluoride, hydrogen chloride $(\mathrm{HCl})$ and particulate matter (PM) [1].
Such technology has been successfully used for medical waste incineration and other industrial applications. The unit causes very little pressure drop, can handle large volume of gases and it can be employed for the dual purpose of absorbing gaseous pollutants while removing particulates. According to USEPA and NACAA [2], the flow dynamics of the gas transporting the particulate matter (PM) and gaseous contaminants into the scrubber system is a key factor which should be considered in designing the system for gas and particle separations. If the drag force of the gas is not sufficient enough to transport the particles within the inlet and outlet ducts and into the scrubbing chamber, the particles may deposit along the duct ways and the chamber and the gas may develop another swirling action within the chamber. Parametric CFD analysis has shown to play a crucial role in the engineering design of fluid-dynamic devices. Without it, engineering methods can be costly and time consuming. An understanding of the stages involved in parametric CFD analysis gives user a better understanding of how that device behaves over its entire operating envelope and quickly 
produces better designs. Hudson [3], Kennedy et al. [4] and Minghua et al. [5] indicated that, computational fluid dynamics (CFD) approach has promising applications in both dry and wet counter-flow scrubber systems for industrial air pollution applications. It has the benefit of developing a virtual prototype which can evaluate and compare design alternatives without material, construction and testing cost, the advantage of enabling and improving engineering design with tight margins, simulating complex fluid flow phenomena at a reduced cost and demonstrating project feasibility prior to construction as in $[6,7,8,9]$.

The main objective of this study is to perform a CFD based parametric numerical analysis of the gas flow dynamics of a counter-flow wet scrubber system so as to explore the velocity and pressure field profiles and optimize the gas-PM flow in the scrubber system so as to avoid dead zone within the systems cross section.

\section{Materials and Method}

\subsection{The Case Study Specifications}

The studied wet scrubber has been designed using hydraulic similitude method by considering data obtained from cement industry as shown in Table 1. Schematic diagram of the system is described in Figure 1.

Table 1. Summary of Kiln Shop Exhaust PM-Laden Gas Data

\begin{tabular}{ll}
\hline Operating Parameter & Operating Data \\
\hline Volume Flow Rate & $104,885 \mathrm{~m}^{3} / \mathrm{hr}$ \\
Mass Flow & $119,084 \mathrm{~kg} / \mathrm{hr}$ \\
Gas Temperature & $105^{0} \mathrm{C}$ \\
Dust Burden (Inlet) & $62,500 \mu \mathrm{g} / \mathrm{m}^{3}$ \\
Dust Burden (Outlet) & $25,000 \mu \mathrm{g} / \mathrm{m}^{3}$ \\
\hline
\end{tabular}

Source: Ashaka Cement Company [10]

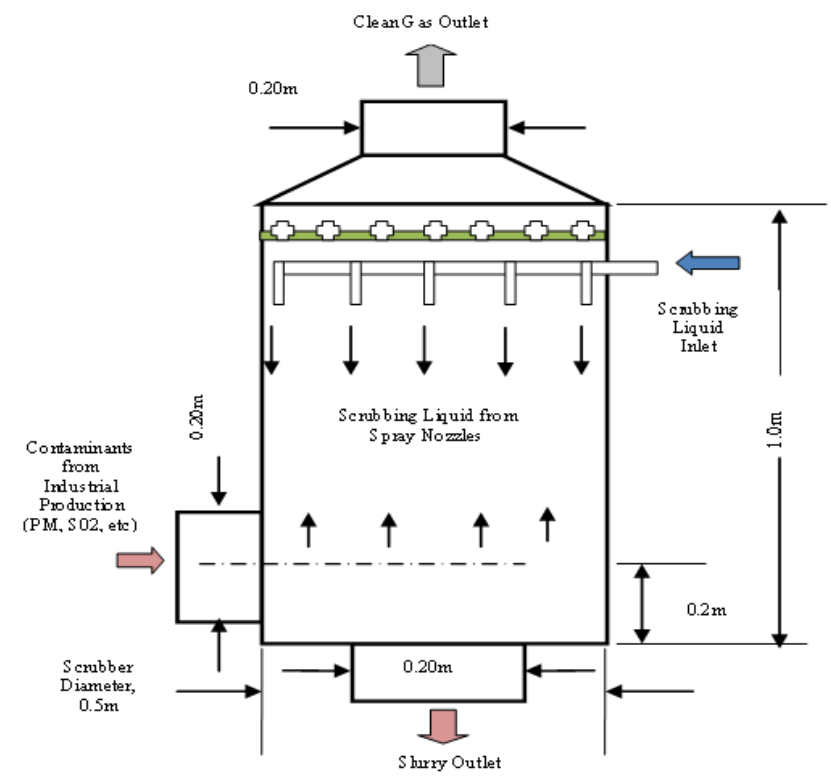

Figure 1. Geometric Sketch of the Scrubber
Considering the fact that, the scrubber gas outflow is our subject of concern in this study; a curved transition using hood design approach was provided so as to create shape and good flow characteristics of the gas out of the scrubber with minimum friction loss. However, this transition was not provided at the slurry exit, because its flow characteristics have not been considered in the study.

\subsection{Mathematical Modeling}

The appropriate governing equations for the gas flow are the incompressible Nervier Stokes Equation (NSE) for a single phase flow obtained from the conservation of mass and momentum described by Caiting, et al. [7].

Continuity equation

$$
\frac{\partial\left(U_{i}\right)}{\partial x_{i}}=0
$$

Momentum equation

$$
\begin{aligned}
& \frac{\rho_{g} \partial\left(U_{g}^{i} U_{g}^{j}\right)}{\partial x_{i}}=-\frac{\partial P}{\partial x_{i}}+ \\
& \frac{\partial}{\partial x_{j}}\left[\mu_{e f f}\left(\frac{\partial U_{g}^{i}}{\partial x_{j}}+\frac{\partial U_{g}^{j}}{\partial x_{i}}\right)\right]+\rho_{g} g_{i}
\end{aligned}
$$

Where, $i$ and $j$ are the direction vectors for the three coordinates $\left(x, y\right.$, and $z$ ) while $U_{g}{ }^{i}$ and $U_{g}^{j}$ are the three velocity components $(u, v, w)$ of the gas flow, $\mu_{e f f}$ is the effective dynamic viscosity of gas, $\rho_{g}$ is the gas density, $P$ is the gas pressure and $\rho g_{i}$ is the gas volume force in $i$-direction respectively.

To avoid the unnecessary consumption of the computer time for the solution of the full-scale, turbulence model for predicting the effects of turbulence in the gas phase should be considered. Averaging is often used to simplify the solution of the governing equations of turbulence, but models are needed to represent scales of the flow that are not resolved. One of the most effective viscosity models for the simulations of the turbulent flow is the Harlow-Nakayama $k-\varepsilon$ model of the turbulent flow described in (3) and (4). The model provides the time averaged values of velocities and pressure of the gas or air throughout the system.

$$
\begin{aligned}
& k-\text { equation } \\
& \rho \frac{\partial\left(k U_{i}\right)}{\partial x_{i}}+\rho U_{j} \frac{\partial k}{\partial x_{j}}= \\
& \frac{\partial}{\partial x_{i}}\left[\left(\mu+\frac{\mu_{t}}{\delta_{k}}\right) \frac{\partial k}{\partial x_{i}}\right]_{+} \\
& \mu_{t} \frac{\partial U_{j}}{\partial x_{j}}\left(\frac{\partial U_{i}}{\partial x_{j}}+\frac{\partial U_{J}}{\partial x_{i}}\right)-\rho \varepsilon
\end{aligned}
$$




$$
\begin{aligned}
& \varepsilon-\text { equation } \\
& \rho \frac{\partial\left(\varepsilon U_{i}\right)}{\partial x_{i}}=\frac{\partial\left[\left(\mu+\frac{\mu_{t}}{\delta_{\varepsilon}}\right) \frac{\partial \varepsilon}{\partial x_{i}}\right]}{\partial x_{i}}+ \\
& \frac{c_{1} \varepsilon}{k} \mu_{t} \frac{\partial U_{i}}{\partial x_{j}}\left(\frac{\partial U_{i}}{\partial x_{j}}+\frac{\partial U_{J}}{\partial x_{i}}\right)-c_{2} \rho \frac{\varepsilon^{2}}{k}
\end{aligned}
$$

Where $k$ is the turbulent kinetic energy, $\varepsilon$ is the turbulent kinetic energy dissipation rate; $\mu_{t}$ is viscosity coefficient of turbulent flow while $\delta_{k}, \delta_{\varepsilon}, c_{1}, c_{2}$ are constants; $c_{1}=1.44, c_{2}$ $=1.92, \delta_{k}=1.0, \delta_{\varepsilon}=1.3$ [7]. The standard $k-\varepsilon$ model was based on the hypothesis of the isotropic eddy-viscosity, which was modeled through the flow fields of the turbulent kinetic energy and the specific dissipation rate. According to [11], the model leads to stable calculations that converges easily and allows reasonable predictions for many flows. Also, [7] indicated that $k-\varepsilon$ is the most commonly used turbulence model which has many advantages; its concept is simple and it has been implemented in many commercial CFD codes. The model has demonstrated the capability to simulate many industrial processes effectively as in $[6,12$, 13, and 14].

\subsection{Numerical Computation Methods}

A dimension of the scrubber in Figure 1 has been used to generate a 3D geometry of the scrubber system using CAD. The geometry was then imported into ANSYS Fluent [15] for processing.

As shown in Figure 2, the pipe geometry for the scrubbing liquid spray and the slurry outlet duct were suppressed from the main geometry so as to analyse only the gas flows across the scrubbing chamber.

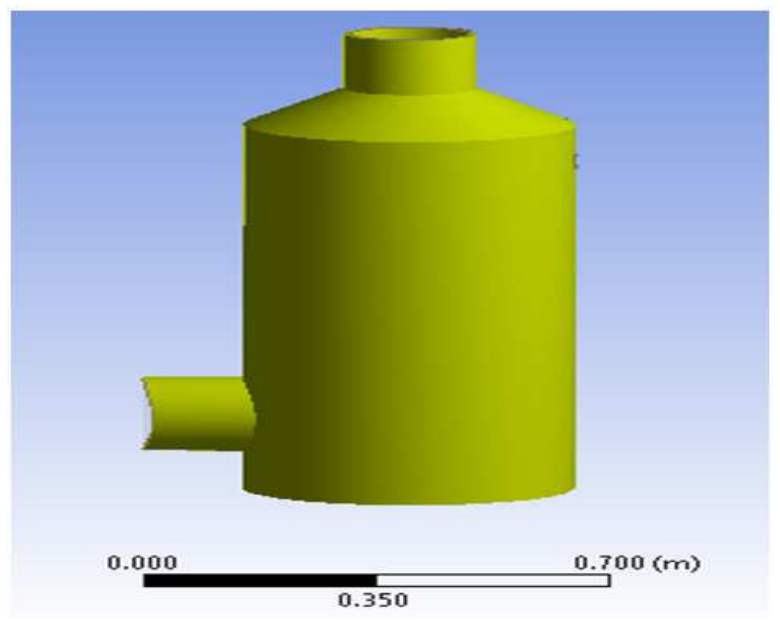

Figure 2. Scrubber Geometries in ANSYS Fluent Workbench

Using the ANSYS Fluent [15] workbench and mesh windows the volume for the flow dynamics was filled and the boundary condition defined. The calculation domain of the scrubber geometry was applied to produce good mesh profile by using efficient meshing parameters such as; the growth rate and mesh refinement as shown in Figure 3.

A growth rate of 1.4 and a refinement of 3 were used across the scrubber inlets, outlets and the wall parts so as to provide a smooth flow transition across the system.

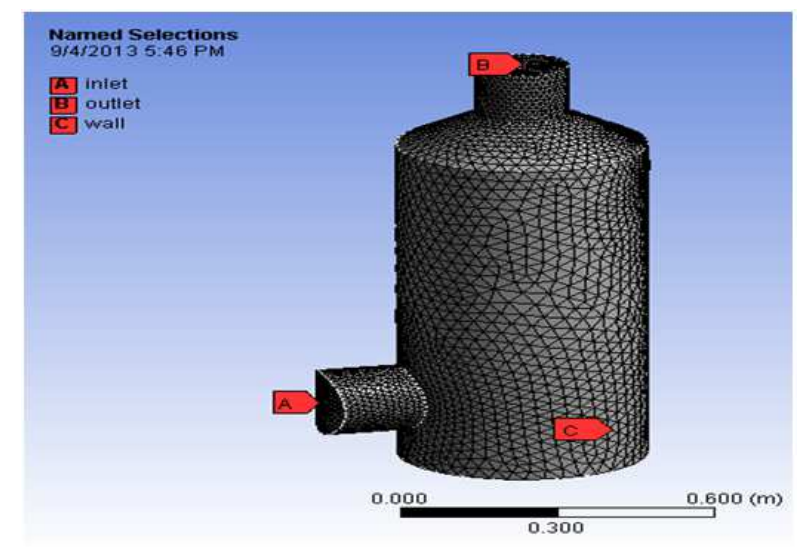

Figure 3. Boundary Condition and Mesh Profile of the Scrubber Geometries

This yielded a statistics of 91,051 nodes and 459,870 elements and an aspect ratio of 5.98832 and skewness of 0.6078. However, these values are within the required range of mesh skewness $\leq 1.0$ and aspect ratio $\leq 10$ respectively. For the boundary condition, velocity inlet has been selected at the gas inlet while pressure outlet was chosen for the gas outlet.

Values for the inlet velocities were chosen from the range of USEPA and NACAA [16], Ngala et al. [17] and Garba [18] recommended PM transport velocities; 0.32, 0.79 and $1.27 \mathrm{~m} / \mathrm{s}$. The simulation starts by identifying and applying conditions at the domain boundaries and then solving the governing equations on the computational mesh iteratively as a steady-state. Since this is a pressure based solution method, the PISO (Pressure Implicit with Splitting of Operators) algorithm recommended by ANSYS Fluent [19] for solving steady flow calculations (especially when the solution involves turbulence model) has been used. Also, [19] indicated that generally for triangular and tetrahedral meshes, a more accurate result is obtained by using the second-order discretization.

There are six differential equations to be solved in 3D which resulted to six residuals for convergence; continuity, $x$-velocity, $y$-velocity, $z$-velocity and $k$ - $\varepsilon$ turbulent equations respectively. The CFD solution were calculated using efficient residual of 1E-6 starting from 50 iterations which were increased to higher value depending on the delay for the solutions to converge. These residuals represent a kind of average error in the solution. An absolute initialization was set to compute from the gas inlet. Considering the fact that, the flow field in the wet scrubber is complicated. The gas flow CFD simulation of the scrubber system is based on the following assumptions: 
1. The gas phase flow was only considered in the scrubber and no liquid phase is taken into account,

2. The flow is stable and isothermal, so heat exchange among the phase is not considered,

3. The gas is regarded as incompressible,

4. The PM transport velocity recommended by USEPA and NACAA [16] was considered for the simulation.

\section{Results and Discussion}

From the simulation experimentations, the residuals does a very good job of converging at approximately 590, 500, and 550 iterations at inlet velocities of $0.32,0.79$ and $1.27 \mathrm{~m} / \mathrm{s}$ as shown in Figures 4, 5 and 6 .

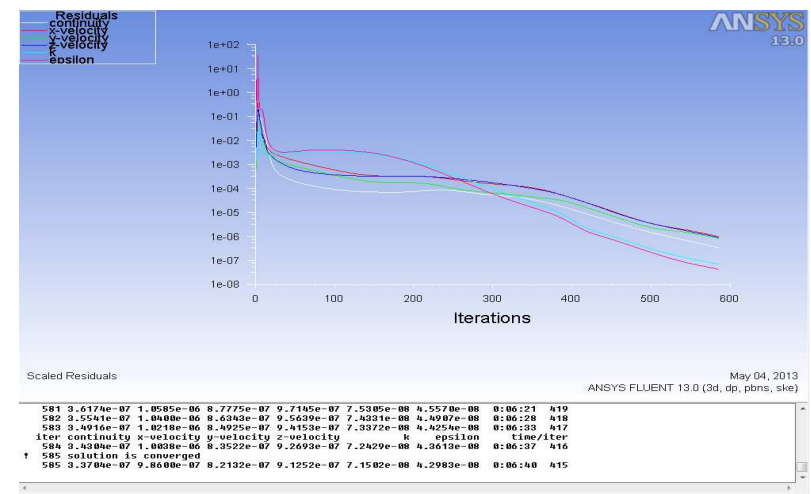

Figure 4. Residuals for the Continuity, $k$-Epsilon and $X, Y, Z$ Velocities at $0.32 \mathrm{~m} / \mathrm{s}$

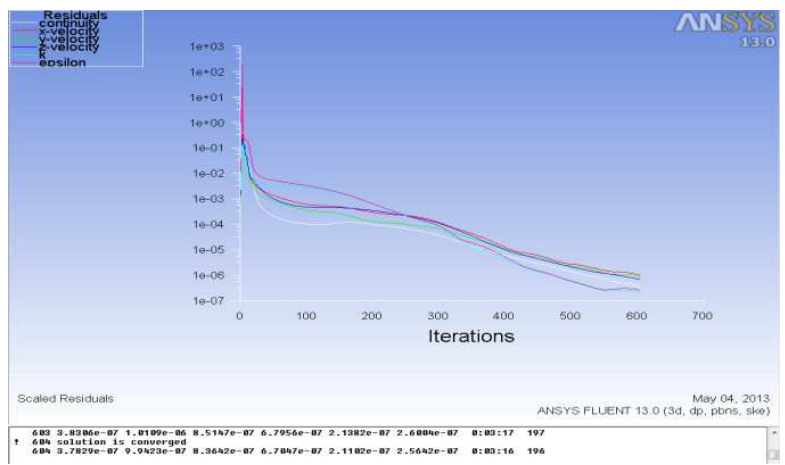

Figure 5. Residuals for the Continuity, $k$-Epsilon and $X, Y, Z$ Velocities at $0.79 \mathrm{~m} / \mathrm{s}$

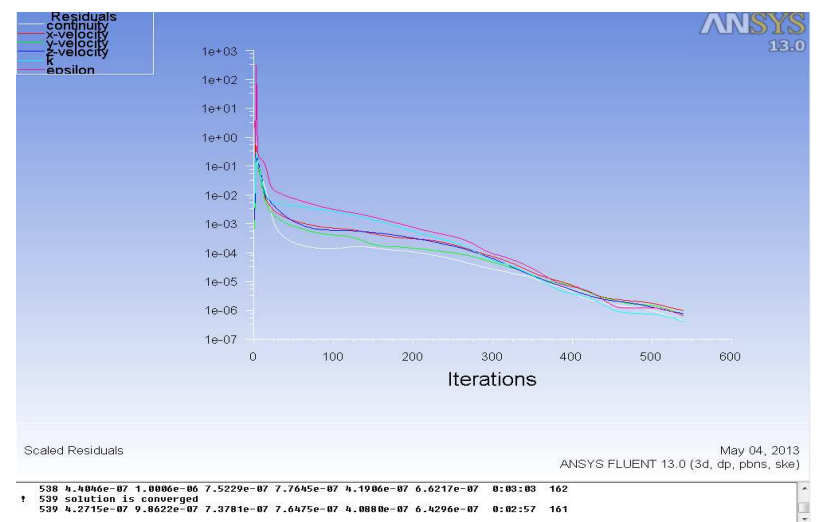

Figure 6. Residuals for the Continuity, k-Epsilon and X. Y, Z at $1.27 \mathrm{~m} / \mathrm{s}$
Graphic displays of the velocity fields which includes velocity contours describing the gas flows from the inlet, across the scrubbing camber to the outlet for the three inlet velocities considered in the study is shown in Figures 7,8 and 9 ( $\mathrm{a}$ and $\mathrm{b}$ )respectively.

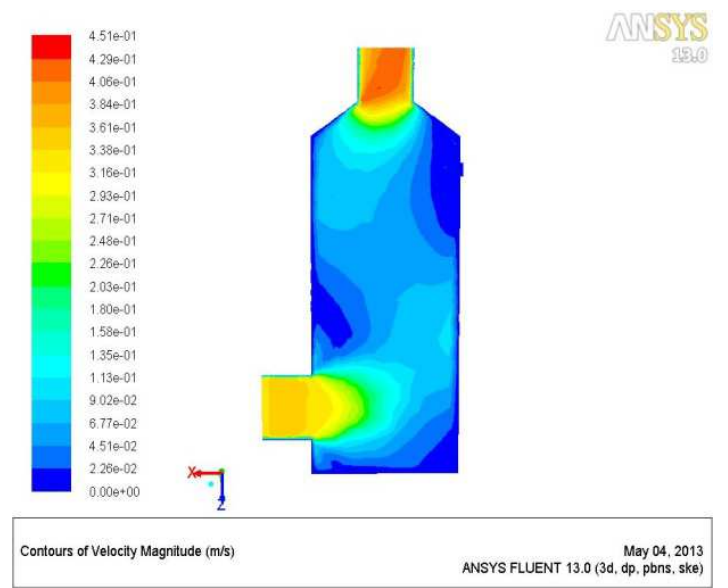

Figure 7a. Y-Coordinate Contour Display of the Gas Flow across the Scrubber at $0.32 \mathrm{~m} / \mathrm{s}$

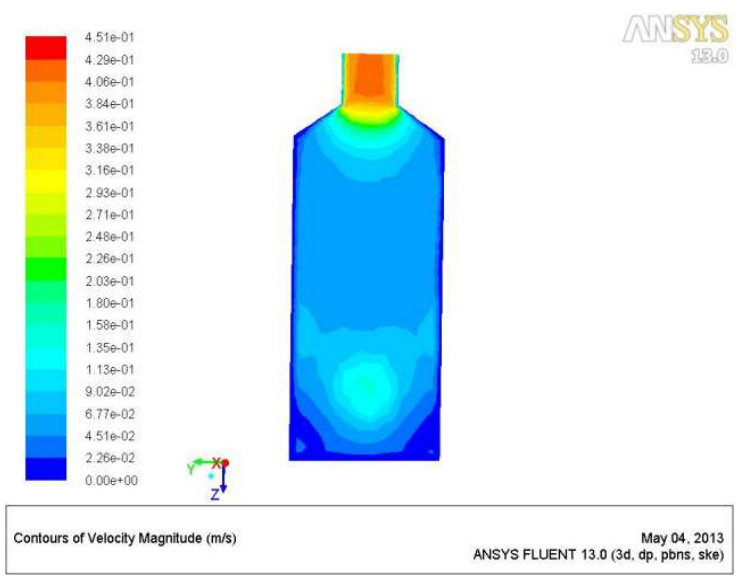

Figure 7b. X-Coordinate Contour Display of the Gas Flow across the Scrubber at $0.32 \mathrm{~m} / \mathrm{s}$

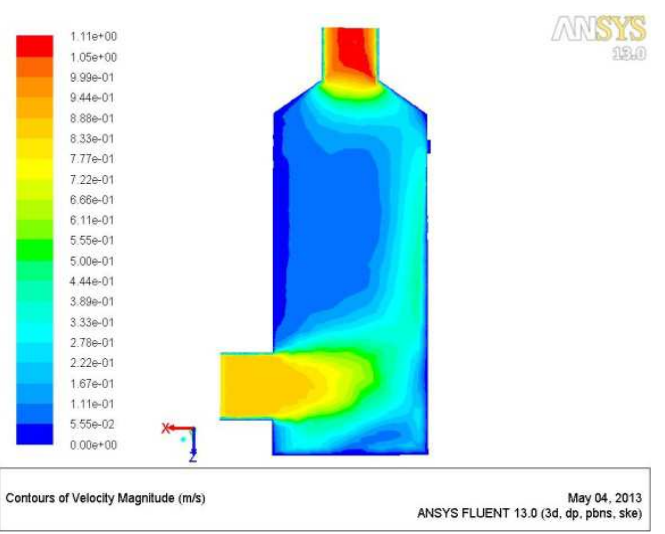

Figure 8a. Y-Coordinate Contour Display of the Gas Flow across the Scrubber at $0.79 \mathrm{~m} / \mathrm{s}$ 

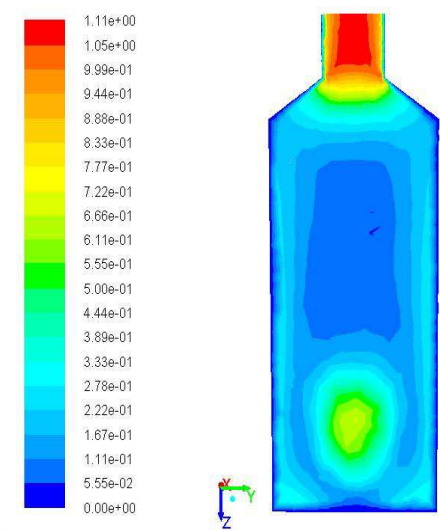

Contours of Velocity Magnitude (m/s)

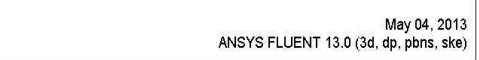

Figure 8b. X-Coordinate Contour Display of the Gas Flow across the Scrubber at $0.79 \mathrm{~m} / \mathrm{s}$

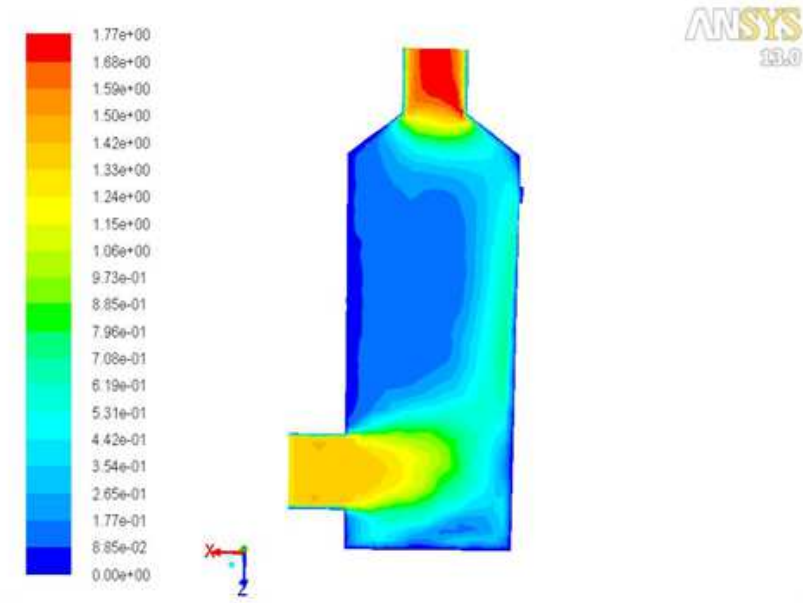

Contours of Velocily Magnitude $(\mathrm{m} / \mathrm{s})$

May 04.2013

Figure 9a. Y-Coordinate Contour Display of the Gas Flow across the Scrubber at $1.27 \mathrm{~m} / \mathrm{s}$
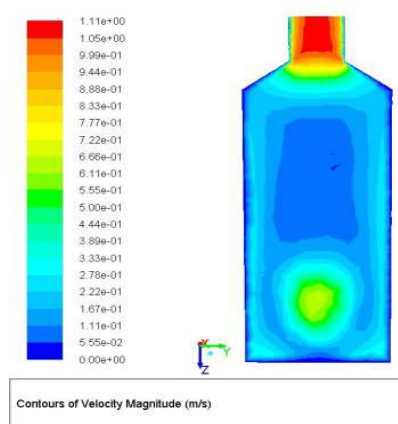

ANSYS FLUENT 13.0 (3ad, May, pans, 2013

Figure 9b. X-Coordinate Contour Display of the Gas Flow across the Scrubber at $0.79 \mathrm{~m} / \mathrm{s}$

The velocity contours in $\mathrm{X}$ and $\mathrm{Y}$ coordinates above describing the gas flow across the scrubber shows a more distributed flow across the spray chamber for a $0.32 \mathrm{~m} / \mathrm{s}$ velocity which are further supported by the velocity vector displays across the chamber shown in Figures 10,11 and 12.

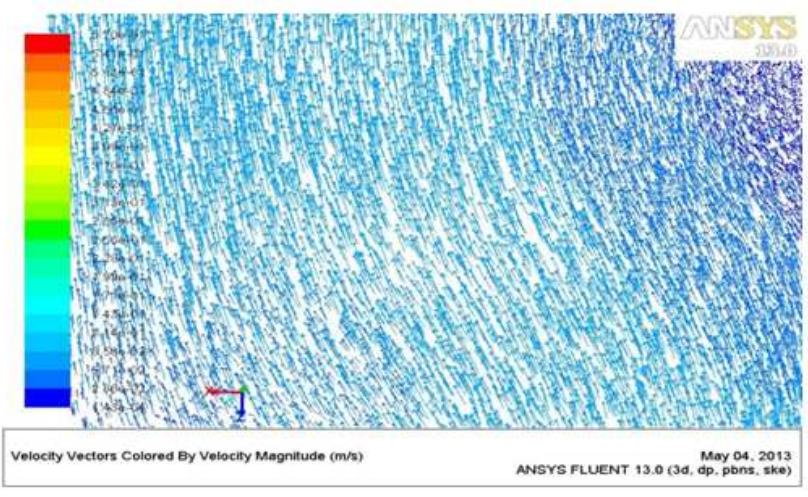

Figure 10. Velocity Vector of the Gas Flow within the Geometry

For the other velocities; 0.79 and $1.27 \mathrm{~m} / \mathrm{s}$, the gas is partially distributed across the centre and fully distributed across the side walls.

Figures 10 and 11 shows a stream line flow along the scrubber inlet and the outlet ducts at $0.32 \mathrm{~m} / \mathrm{s}$ which have conformed to the Bernoulli's theorem

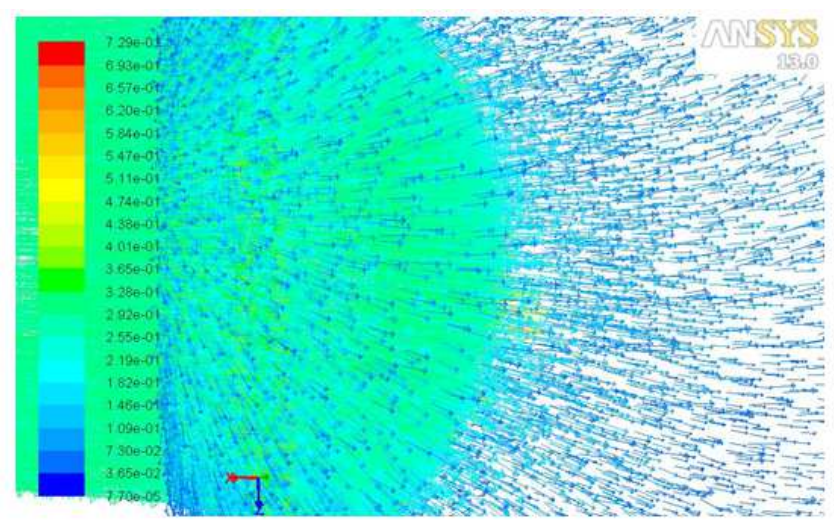

Figure 11. Velocity Vector of the Gas Flow at Inlet $0.32 \mathrm{~m} / \mathrm{s}$

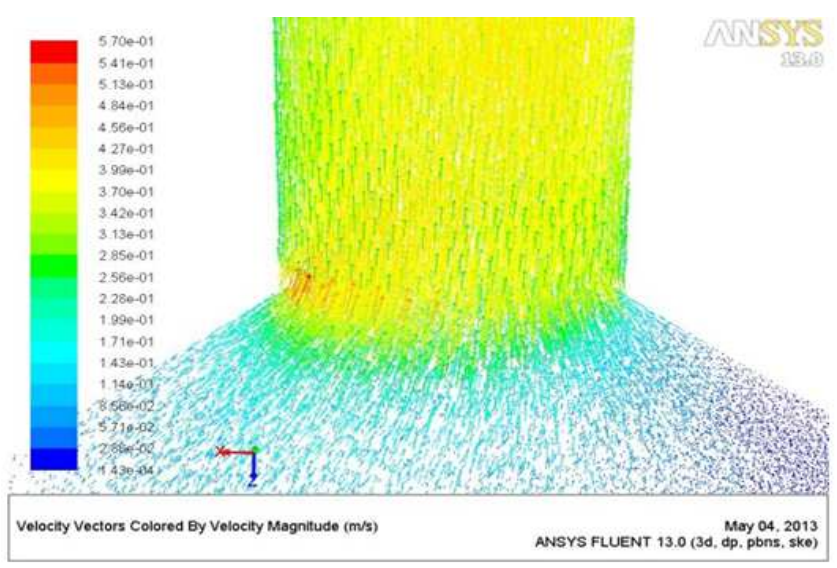

Figure 12. Velocity Vector of the Gas Flow towards the Exit at $0.32 \mathrm{~m} / \mathrm{s}$

Not all fluid particles travel at the same velocity within a cylindrical pipe. The shape of the velocity curve which is the velocity profile across any given section of the pipe depends upon whether the flow is laminar or turbulent as shown in Figure 13 [20, 21]. 


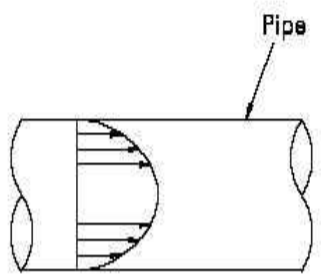

Lominar Flow

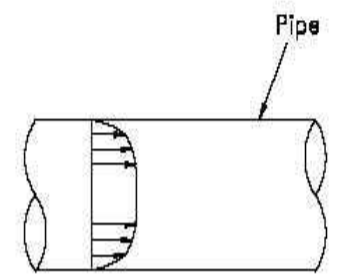

Turbulent Flow
Figure 13. Velocity Profile across a Cylindrical Pipe for Laminar and Turbulent Flows

As shown in figure 13, if the flow in a pipe is laminar, the velocity distribution at a cross section will be parabolic in shape with the maximum velocity at the centre being about twice the average velocity in the pipe.

In turbulent flow, a fairly flat velocity distribution exists across the section of pipe, with the result that the entire fluid flows at a given single value.

The velocity of the fluid in contact with the pipe wall is essentially zero and increases the further away from the wall. To validate the gas flow into the scrubber system, velocity profiles for the three velocities along the inlet duct was plotted as shown in Figures 14, 15 and 16.

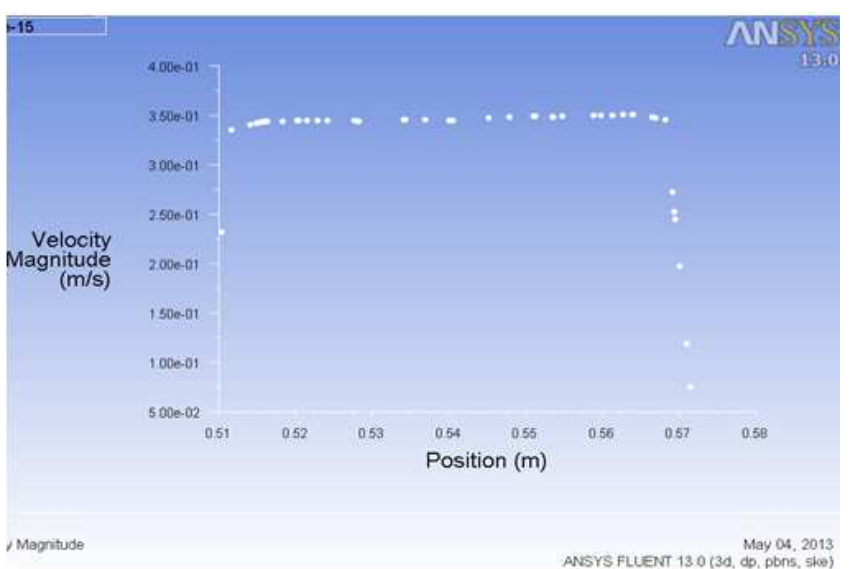

Figure 14. Velocity Profile for the Inlet Gas at $0.32 \mathrm{~m} / \mathrm{s}$

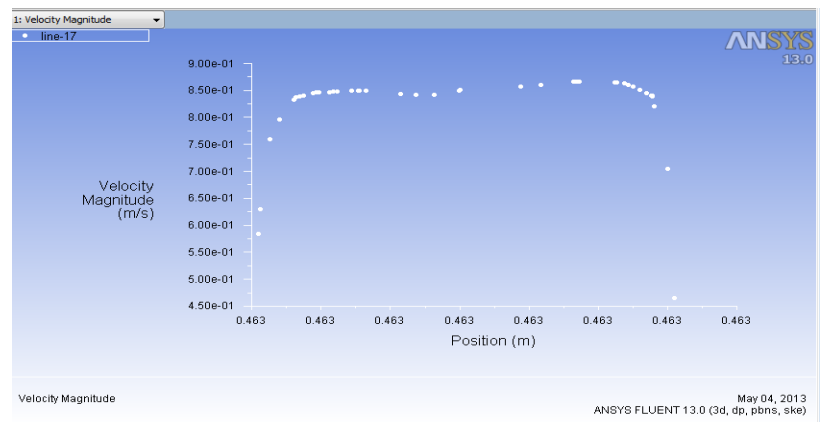

Figure 15. Velocity Profile for the Inlet Gas at $0.79 \mathrm{~m} / \mathrm{s}$

Since turbulent model was considered in the CFD simulation, from the above figures it can be seen that the velocity profiles has fully conformed to the recommended profile for turbulent flows in pipes and cylinders.

According to USEPA and NACAA [16], pressure drop across a wet scrubber system is an important parameter in evaluating the performance and operations of the system especially for PM removal. The pressure drop is a measurement of the resistance to flow as the gas passes from one point to another point and is simply the arithmetic difference between the static pressure at the scrubber inlet and outlet (measured at right angles to the flow). The value of the pressure drop takes into account the amount of energy loos during wet scrubbing process. According to [22], the system pressure is computed using the gauge pressure (pressure measured in a system) and the atmospheric pressure given as;

$$
P_{\text {system }}=P_{\text {gauge }}+P_{\text {atm }}
$$

The ANSYS Fluent [15] uses pressure gauge to measure the static pressure which is also the scrubber systems pressure at the inlet and outlet as shown in Figures 17a, 17b and $17 \mathrm{c}$ for the three velocities.

As shown above, for the $0.32 \mathrm{~m} / \mathrm{s}$ velocity the static gauge pressure was obtained to be $0.309 \mathrm{pa}$ and 0.0164 at the inlet and the outlet of the system. Also, for the $0.79 \mathrm{~m} / \mathrm{s}$, the static gauge pressure was obtained to be $1.32 \mathrm{pa}$ and $0.00442 \mathrm{pa}$ at the inlet and outlet. However, a static gauge pressure of $3.16 \mathrm{pa}$ and $0.131 \mathrm{pa}$ at the inlet and outlet for the $1.27 \mathrm{~m} / \mathrm{s}$ was obtained. The pressure drop, $\Delta P$ for the three flows velocities was computed using the relation

$$
\Delta P=P_{\text {system (1) }}-P_{\text {system (2) }}
$$

Comparison between the dynamic similitude pressure obtained from the recommended pressure drop for spray tower scrubber and the computed pressure drop from the CFD analysis shown in Table 2 indicated a closer agreement between the two.

Table 2. Comparison between the Recommended and Computed Pressure Drop

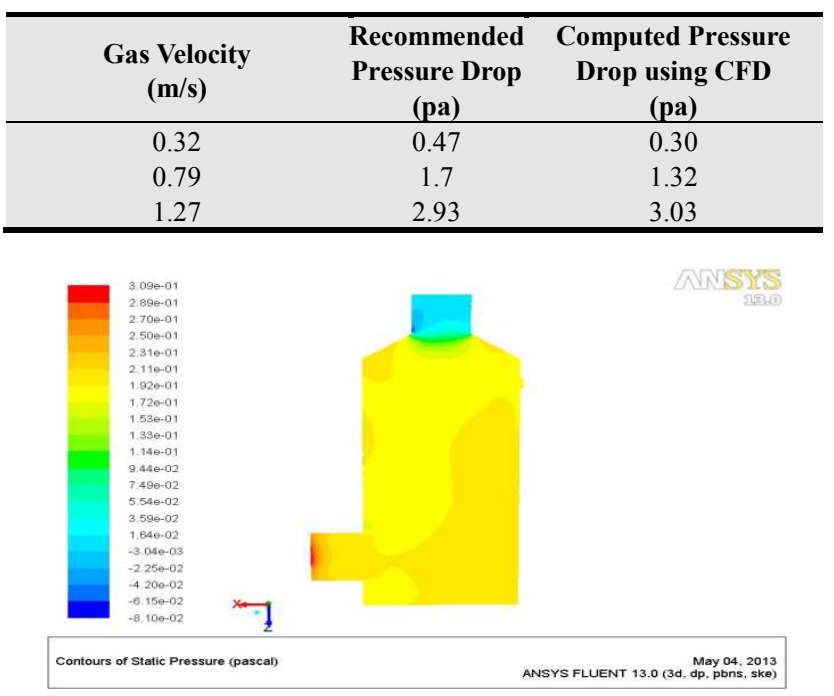

Figure 16a. Contour Display of Static Pressure at $0.32 \mathrm{~m} / \mathrm{s}$ 


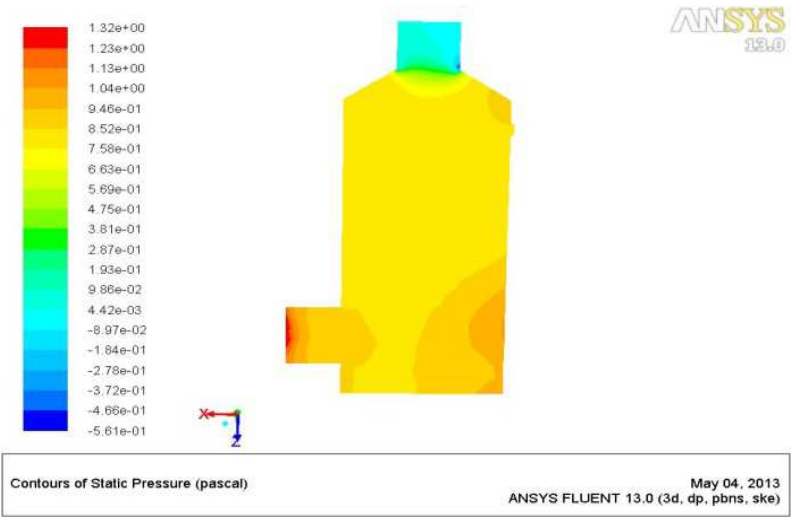

Figure 16b. Contour Display of Static Pressure at $0.79 \mathrm{~m} / \mathrm{s}$

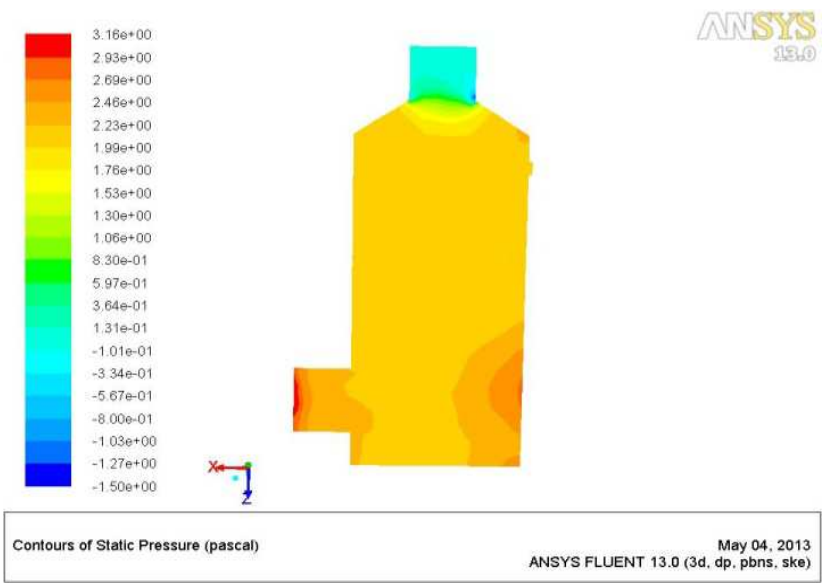

Figure 16c. Contour Display of Static Pressure at $1.27 \mathrm{~m} / \mathrm{s}$

The study of pressure across any fluid system arise from the Bernoulli's equation which is significant in the study of an incompressible fluid flow that is fundamental to an understanding of the design and operations of most fluid based devices. Simplified form of Bernoulli's equation is described by the word equation as;

$$
\text { Static }+ \text { Dynamic }=\text { Constant }
$$

Equation (7) above indicated that the sum of flow static and dynamic pressure is constant along a streamline of fluid flow.

According to [20], the sum of these two pressures is termed as the total pressure. Figures $18 \mathrm{a}, 18 \mathrm{~b}$ and $18 \mathrm{c}$ shows total pressure contours for the three velocities. For $0.32 \mathrm{~m} / \mathrm{s}$ velocity which is the velocity at which the scrubber performed optimally in the simulation analysis, the total pressure is almost constant across the spray chamber. But the pressure is higher across the inlet and slightly lower along the exit. For 0.79 and $1.27 \mathrm{~m} / \mathrm{s}$ velocities, the total pressure is slightly higher and approximately constant within the chamber. This indicated that the proposed scrubber has conformed to the Bernoulli's equation especially at velocity of $0.32 \mathrm{~m} / \mathrm{s}$. Total Pressure at $0.32 \mathrm{~m} / \mathrm{s}$ $1.27 \mathrm{~m} / \mathrm{s}$

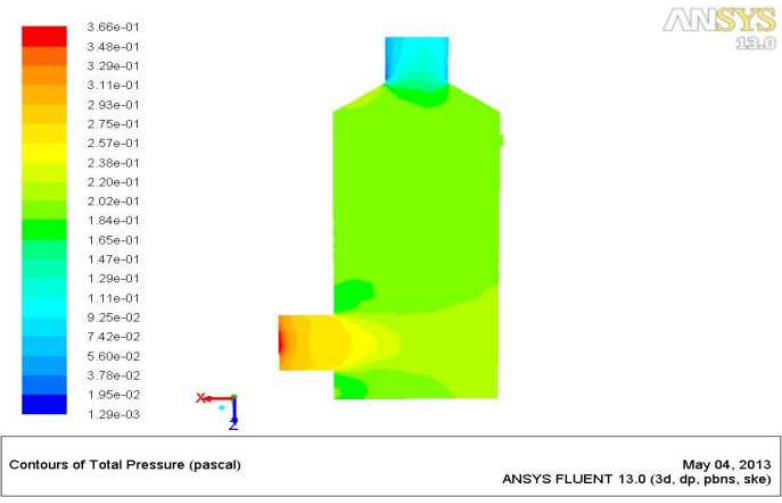

Figure 17a. Contour Displays of Total Pressure at $0.32 \mathrm{~m} / \mathrm{s}$

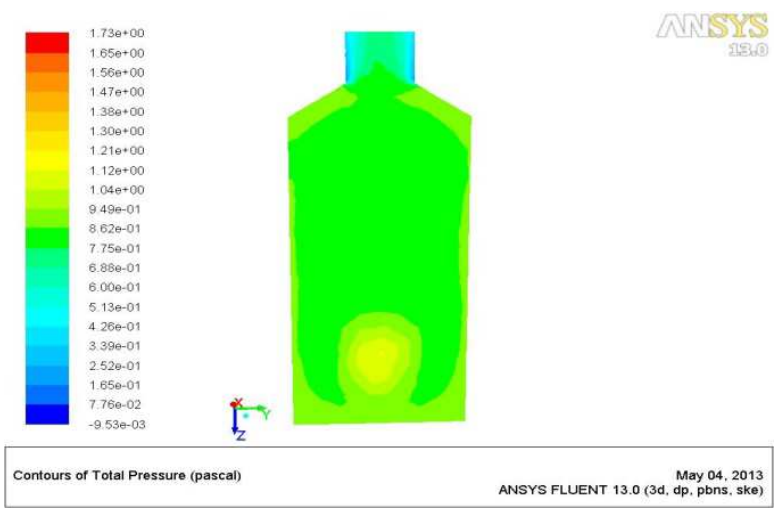

Figure 17b. Contour Displays of Total Pressure at $0.79 \mathrm{~m} / \mathrm{s}$

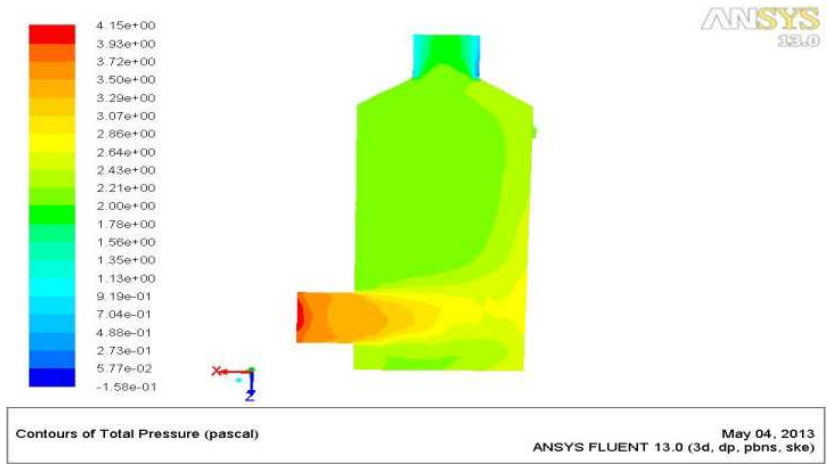

Figure 17c. Contour Displays of Total Pressure at $1.27 \mathrm{~m} / \mathrm{s}$

\section{Conclusion}

ANSYS Fluent software has been used to investigate the gas distribution within a counter-flow wet scrubber system based on airflow velocity and pressure fields. The velocity flow contours and vectors at the inlet, across the scrubbing chamber and the outlet (especially at $0.32 \mathrm{~m} / \mathrm{s}$ ) shows a distributed flow and the velocity profiles have fully conformed to the recommended profile for turbulent flows in cylindrical pipes. The total pressure within the scrubber cross-section is constant which follows the Bernoulli's principle. The minimum pressure drop, $\Delta P_{\min }$ for the scrubber system was obtained to be $0.30 \mathrm{pa}$ and the maximum, $\Delta P_{\max }$ was 3.03 pa which has conformed to the recommended pressure drop for wet scrubbers. From the par- 
ametric analysis conducted, it can be concluded that the numerical simulation using Ansys Fluent CFD is an effective method of studying the flow characteristics of a counter-flow wet scrubber system.

\section{References}

[1] Frank, R. S. and Nancy, W. E. 2005. Environmental Engineers Mathematics Handbook, CRC Press, Florid, USA, pp. 208-249.

[2] United States Environmental Protection Agency (USEPA) and National Association of Clean Air Agencies (NACAA). 2012. Control of Particulate Matter Emissions. APTI 413 Module 8 Student Manual, 39-40. Online: (www.epa.gov/apti/Materials/APTI413student/413StudentM anual/SM_ch8.pdf).

[3] Hudson Product Corporation. 2011. Air Cooled Heat Exchanger Modeling with CFD.

[4] Kennedy, C., Diwakar, P., Leonad, J.R. and Rosendall, B. 2011. Computation Based Engineering of Multiphase Process Using CFD, Bechtel Technology Journal, vol. 3, No. 1.

[5] Minghua, B., Qiufang W. and Yu, Z. 2010. Numerical Simulations of Dust Removal Device for Quicklime Slacking, Environmental and Chemical Engineering College, Yanshan University.

[6] Goniva C., Pirker, S., Tukovoc, Z., Feilmayr, C. and Burgler, T. 2009. Simulation of Off-Gas Scrubbing by a Comgined Eulerian-Lagrangian Model, $7^{\text {th }}$ International Conference on CFD in the Minerals and Processing Industries, Melbourne, Australia.

[7] Caiting L., Shanhong L., Guangming, Z., Fei W., Dayong W., Hongliang, G. And Wei G. 2008. Airflow Simulation of an Umbrella Plate Scrubber, IEEE Conference Publications, The $2^{\text {nd }}$ Conference on Bioinformatics and Biomedical Engineering, (ICBBE-2008), Shanghai, China.

[8] Shan-hong L., Cai-ting L, Guang-ming Z., Si-min L., Fei W. and Da-yong W. 2008. CFD Simulation on Performance of New type Umbrella Plate Scrubber, Transactions of Nonferrous Metals Society of China, vol. 18, pp 488-492.

[9] Dudek, S .A., Rogers, J. A. and Gohara, W. E. 1999. Computational Fluid Dynamics (CFD) Model for Predicting a Two-Phase Flow in Flue Gas Desulfurization Wet Scrubber,
EPRI-DOE-EPA Combined Utility in Air Pollution Control Symposium, Atlanta, Georgia, USA.

[10] Ashaka Cement plc., Gombe State, Nigeria. 2011.

[11] Karthik, T. S. D. 2011. Turbulence Models and their Applications, Department of Mechanical Engineering, Indian Institute of Technology, Madras, India.

[12] Hendawi, M., Molle B. And Folton C. 2005. Measurement Accuracy Analysis of Sprinkler Irrigation Rainfall in Relation to Collector Shape, Journal of Irrigation and Drainage Engineering, vol. 131, no. 5, pp. 477-483.

[13] Lee, C. W., Palma, P. C. and Simmons, K. 2005. Comparison of Computational Image Velocimetry Data for the Airflow in an Aero-engine Bearing Chamber, Journal of Engineering for Gas Turbines and Power, vol. 127, no. 4, pp. 697-703.

[14] Xiang, R. B. And Lee, K. W. 2005. Numerical Study of Flow Field in Cyclones of Different Height, Journal of Chemical Engineering Process, vol. 44, no. 8, pp. 877-883. ANSYS Fluent 13.0 Inc., 2010. USA.

[15] United States Environmental Protection Agency (USEPA) and the National Association of Clean Air Agencies (NACAA). 2010. APTI: 413 Control of Particulate Matter Emissions , 5th Edition, Chapter 10 Student Manual. Online: (http://www.epa.gov/apti/Materials/APTI\%20413\%20studen $\mathrm{t} / 413 \% 20$ Student $\% 20$ Manual/SM ch\%2010.pdf).

[16] Ngala, G. M. Sulaiman, A. I. and Sani, M. U. 2008. Air Pollution Control in Cement Factory Using Horizontal Type Wet Scrubber, Continental Journal of Applied Sciences, vol. 3, No. 1.

[17] Garba, M. N. 2005. Gas Particle Separation Using Wet Scrubber Method, M.Eng Thesis, Department of Mechanical Engineering, Bayero University Kano, Nigeria.

[18] ANSYS Fluent 12.0 Inc., 2009. USA.

[19] Yunus A. C. and John M. C. 2006. Fluid Mechanics: Fundamentals and Applications, International Edition, McGraw Hill Publication, pp.185-201.

[20] Munson, B. R., Young, D. F., Okishi, T. H. and Huebsch. 2010. Fundamentals of Fluid Mechanics, Sixth Edition, John Wiley and Sons, pp. 332-374.

[21] Engireering ToolBox, 2013. Online: (http://www.engineeringtoolbox.com/). 